\title{
AUG 221922
}

\author{
DEPARTMENT OF COMMERCE. \\ BUREAU OF STANDARDS. \\ S. W. STRATTON, Director
}

CIRCULAR OF THE BUREAU OF STANDARDS.

No. 123.

Issued July 27, 1922.

\section{UNITED STATES GOVERNMENT SPECIFICATION FOR WHITE FLOATING SOAP.}

\section{FEDERAL SPECIFICATIONS BOARD.}

STANDARD SPECIFICATION No. 26.

This Specification was officially adopted by the Federal Specifications Board on June 20, 1922, for the use of the Departments and Independent Establishments of the Government in the purchase of materials covered by it.

\section{CONTENTS.}

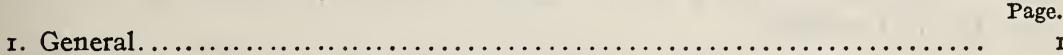

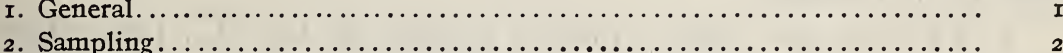

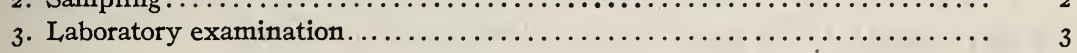

4. Reagents..................................... 5

\section{GENERAL.}

The soap desired under this specification is a high-grade cake soap, at least as good in every respect as one made from soda and a mixture of high-grade tallow with 25 to 30 per cent of coconut oil, of good light color, thoroughly saponified, and so prepared as to float on water. Bidder shall state size, weight, and number of cakes in each box.

Failure to meet any of the following requirements will be cause for rejection:

Matter volatile at $105^{\circ} \mathrm{C}$. shall not exceed 34 per cent. . Deliveries which yield more than 34 per cent volatile matter will be rejected without further test.

The sum of free alkali, total matter insoluble in alcohol, and sodium chloride shall not exceed 2.0 per cent. 
Free alkali, calculated as sodium hydroxide $(\mathrm{NaOH})$, shall not exceed o.I 5 per cent.

Chloride, calculated as sodium chloride $(\mathrm{NaCl})$, shall not exceed I per cent.

Matter insoluble in water shall not exceed 0.2 per cent.

Rosin, sugar, and foreign matter shall not be present.

The acid number of the mixed fatty acids prepared from the soap must be not less than 2 I 2 .

Odor and character of cake must be as specified by the purchaser.

The percentage of matter volatile at $105^{\circ} \mathrm{C}$. will be computed on the basis of the soap as received, but all other constituents will be calculated on the basis of material containing 28 per cent of volatile matter.

The material will be purchased by net weight, provided the matter volatile at $105^{\circ} \mathrm{C}$. does not exceed 28 per cent. With deliveries containing more than 28 per cent but not exceeding 34 per cent of matter volatile at $105^{\circ} \mathrm{C}$. settlement will be made on the basis of 28 per cent of matter volatile at $105^{\circ} \mathrm{C}$.; that is, seventy-two one-hundredths of a pound of nonvolatile matter shall be considered I pound of soap.

Examples.-I. Yield 27 per cent of matter volatile at $105^{\circ} \mathrm{C}$., pay for net weight.

2. Yield 30 per cent of matter volatile at $105^{\circ} \mathrm{C}$., percentage of net weight to be paid for is calculated as follows:

$$
(\mathrm{IOO}-30) \times \frac{\mathrm{IOO}}{72}=97.22 \text { per cent. }
$$

\section{SAMPLING.}

One cake shall be taken at random from not less than I per cent of the vendors' shipping containers, provided such containers contain not less than 50 pounds each. In the case of smaller containers a cake shall be taken at random from each lot of containers totaling not to exceed 5,000 pounds. The total sample shall in all cases consist of not less than three cakes taken at random from separate containers. With very large lots, where the sample drawn as above will amount to more than 20 pounds the percentage of packages sampled shall be reduced, so that the amount drawn shall not exceed 20 pounds.

Wrap the individual cakes tightly in paraffined paper at once and seal by rubbing the edges with a heated iron. The inspector 
should accurately weigh each wrapped cake, record its weight and the date of weighing on the wrapper, place the wrapped cakes in an air-tight container, which should be nearly filled, seal, mark, and send to the laboratory for test. Samples should be kept cool until tested. The seller shall have the option of being represented at the time of sampling and when he so requests shall be furnished with a duplicate sample.

\section{LABORATORY EXAMINATION.}

(a) Preparation of Sample.-In case of samples that can be easily disintegrated and mixed, run the entire sample through a suitable chopper, except where the sample is large, when each cake may be quartered and one-quarter of each cake run through the chopper. With samples that can not be handled as above, select a cake of average weight, quarter by cutting at right angles in the center, and shave equally from all freshly cut surfaces sufficient soap for analysis. Mix and weigh out all portions for analysis promptly. Preserve the remainder in an air-tight container in a cool place.

When a determination shows nonconformity with specification a duplicate shall be run.

(b) Matter Volatile at $105^{\circ}$ C.-Weigh $5 \mathrm{~g}$ of the sample in a porcelain or glass dish about 6 to $7 \mathrm{~cm}$ in diameter and $4 \mathrm{~cm}$ deep, dry to constant weight in a vacuum oven or an inert atmosphere at a temperature not exceeding $105^{\circ} \mathrm{C}$. (Note.Time can be saved by having a layer of about $3 \mathrm{~mm}$ of ignited sand and a small stirring rod weighed with the dish, and dissolving the sample in absolute alcohol, evaporating to dryness, breaking up the sample with the rod, adding more alcohol, again evaporating and completing the drying in the oven as above.) Report loss in weight as matter volatile at $105^{\circ} \mathrm{C}$.

(c) Total Matter Insoluble in Alcohol, Free Alkali, OR FREE ACID.-(I) Matter Insoluble in Alcohol.-Digest hot a Io $\mathrm{g}$ sample with $200 \mathrm{cc}$ of freshly boiled neutral ethylalcohol (94 per cent or higher). Filter through a counter-poised filter paper neutral to phenolphthalein, or a weighed Gooch crucible with suction, protecting the solution during the operation from carbon dioxide and other acid fumes. Wash the residue on the paper, or in the crucible, with hot neutral alcohol until free from soap. Dry the filter paper, or crucible, and residue at 100 to $105^{\circ} \mathrm{C}$. for three hours, cool, and weigh the total matter insoluble in alcohol.

(2) Free Alkali or Free Acid.-Titrate the filtrate from the above, using phenolphthalein as indicator, with standard acid or 
alkali solution, and calculate the alkalinity to sodium hydroxide (or potassium hydroxide) or acidity to oleic acid.

(3) Matter Insoluble in Water.-Proceed as in the determination of matter insoluble in alcohol. After filtering and thoroughly washing the residue, extract it with water at $60^{\circ} \mathrm{C}$. and wash the filter thoroughly. (When the matter insoluble in water is all inorganic, boiling water may be used for the extraction and washing.) Dry the filter and residue at 100 to $105^{\circ} \mathrm{C}$. for three hours, cool, and weigh matter insoluble in water. The nature of this may be determined by further examination.

(d) Chloride.-Dissolve $5 \mathrm{~g}$ of the sample in $300 \mathrm{cc}$ of water, boiling, if necessary, to effect solution of all soluble matter. Add an excess of neutral chlorine-free magnesium nitrate solution (about 25 cc of a 20 per cent $\mathrm{Mg}\left(\mathrm{NO}_{3}\right)_{2} \cdot 6 \mathrm{H}_{2} \mathrm{O}$ solution). Without cooling or filtering titrate with standard silver nitrate solution, using potassium chromate as indicator. Calculate the chloride as sodium chloride.

(e) Acid Number.-(I) Preparation of Fatty Acids.-Dissolve about $50 \mathrm{~g}$ of the soap in $300 \mathrm{cc}$ of hot water, transfer to a separatory funnel, add $I_{50} \mathrm{Cc}$ of approximately $2 \mathrm{~N} \mathrm{H}_{2} \mathrm{SO}_{4}$, cool somewhat, add I2O cc of ether, shake, draw off the acid layer, and wash the ether layer free from acid with a strong salt $(\mathrm{NaCl})$ solution. Then draw off the aqueous layer as completely as possible, transfer the ether layer to a flask (it is not necessary to transfer quantitatively), add 20 to $30 \mathrm{~g}$ of anhydrous sodium sulphate $\left(\mathrm{Na}_{2} \mathrm{SO}_{4}\right)$, stopper the flask, shake, and let stand at a temperature below $25^{\circ} \mathrm{C}$. until the ethereal liquid becomes perfectly clear, showing that all water has been taken up by the sodium sulphate. Filter through a dry paper into another Erlenmeyer flask and completely evaporate off the ether by passing through the flask a current of dry air while heating the flask to a temperature not above $50^{\circ} \mathrm{C}$.

(2) Determination.-In a 250 cc Erlenmeyer flask dissolve about $2 \mathrm{~g}$ of the fatty acids accurately weighed in 20 to $30 \mathrm{cc}$ of neutral 95 per cent ethyl alcohol. Titrate with standard alkali, using phenolphthalein as indicator. Calculate the acid number ( $\mathrm{mg}$ of $\mathrm{KOH}$ per $\mathrm{g}$ of fatty acids).

(f) Rosin.-A qualitative test for rosin may be made as follows: After decomposing a solution of the soap and separating the fatty acids heat a small quantity of the latter with acetic anhydride, cool, place a few drops on a spot plate, and add a drop of $\mathrm{H}_{2} \mathrm{SO}_{4}$ (specific gravity $=\mathrm{r} .53$ ) to this. A fugitive violet color indicates the presence of rosin. 
(g) SUGAR.-A qualitative test for sugar may be made as follows: Add a decided excess of hydrochloric acid to a solution of the soap, heat on a steam bath for I 5 minutes, cool, filter from fatty acids, and test a portion of the filtrate, which has been neutralized with sodium hydroxide solution, by boiling for two minutes with an equal volume of boiling Fehling solution. The formation of red cuprous oxide indicates the presence of sugar.

\section{REAGENTS.}

(a) Standard Sodium Hydroxide Solution. -0.25 N, or about Io $\mathrm{g}$ sodium hydroxide dissolved in water and diluted to I liter. Standardized against Bureau of Standards benzoic acid.

(b) Standard Sulphuric Acid Solution.-0.5 N, or about $25.8 \mathrm{~g}$ strong sulphuric acid (specific gravity $=\mathrm{I} .84$ ) diluted to I liter. Standardized against standard sodium hydroxide solution (a).

(c) Standard Silver Nitrate Solution.- - Io N, or about I7 $\mathrm{g}$ of silver nitrate dissolved in water and diluted to I liter. Standardized against chemically pure sodium chloride.

(d) SUlPHURIC ACID (SPECIFIC GRAVITY = I.53). - Mix $62.5 \mathrm{cc}$ of strong sulphuric acid (specific gravity $=\mathrm{I} .84$ ) with $6 \mathrm{I} .5 \mathrm{cc}$ of water.

(e) FEHLing Solution.-(I) Copper Sulphate Solution.-Dissolve $34.639 \mathrm{~g}$ of copper sulphate $\left(\mathrm{CuSO}_{4} \cdot 5 \mathrm{H}_{2} \mathrm{O}\right)$ in water and dilute to $500 \mathrm{cc}$.

(2) Alkaline Tartrate Solution.-Dissolve I73 g of Rochelle salts $\left(\mathrm{NaK}_{4} \mathrm{H}_{4} \mathrm{O}_{6} \cdot 4 \mathrm{H}_{2} \mathrm{O}\right)$ and $50 \mathrm{~g}$ of sodium hydroxide in water and dilute to $500 \mathrm{cc}$. Mix equal volumes of (I) and (2) immediately before use.

(f) Potassium Chromate Solution.-A io per cent solution of potassium chromate $\left(\mathrm{K}_{2} \mathrm{CrO}_{4}\right)$ in water.

(g) Standard Alcoholic Sodium Hydroxide Solution.Same as $(a)$, excepting that ethyl alcohol (94 per cent or higher) is used instead of water.

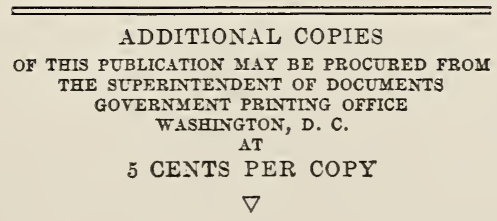





